\title{
ANALISIS KESALAHAN SISWA MENYELESAIKAN SOAL PEMAHAMAN KONSEP PADA MATERI RELASI DAN FUNGSI
}

\author{
Joni Sadarlah Halawa ${ }^{1)}$ \\ Maria Regina Rosari Devita Heksa Oktaviani ${ }^{2)}$ \\ 1),2),3) Program Studi Pendidikan Matematika, Universitas Sanata Dharma \\ Email: ${ }^{1)}$ sadar2johal@gmail.com \\ ${ }^{2)}$ devita.heksa@gmail.com
}

\begin{abstract}
ABSTRAK
Pemahaman konsep pada pelajaran matematika mampu membantu siswa untuk menyelesaikan soal matematika dengan baik dan benar. Akan tetapi, berdasarkan data yang diperoleh dari Kemendikbud (2019) hasil rata-rata nilai Ujian Nasional di Indonesia pada mata pelajaran matematika menduduki peringkat paling rendah di antara mata pelajaran lainnya. Banyak siswa mengalami kesulitan menyelesaikan soal karena tidak paham terhadap konsep yang dipelajari, salah satunya pada materi relasi dan fungsi. Data dari Kemendikbud menunjukkan bahwa hanya $27,14 \%$ siswa yang dapat menjawab soal dengan benar, oleh karenanya peneliti tertarik untuk mengetahui letak kesalahan yang sering dilakukan siswa dalam menjawab soal-soal pada materi relasi dan fungsi. Penelitian ini merupakan penelitian deskriptif kualitatif dengan subjek penelitian sebanyak 50 siswa dari salah satu SMP Negeri di Kabupaten Sleman. Teknik pengumpulan data dilakukan dengan pemberian 5 soal uraian dan jawaban siswa dikumpulkan untuk dianalisis menggunakan analisis kesalahan Newman. Soal yang diberikan mengacu pada karakteristik soal pemahaman konsep yang telah tervalidasi. Hasil menunjukan bahwa jumlah kesalahan terbanyak dilakukan siswa pada tahapan memahami soal yakni sebesar 33\% dan kesalahan paling kecil diperoleh pada tahapan transformasi yakni sebesar 5\%. Penelitian ini penting untuk diteliti karena melihat pemahaman konsep siswa terhadap suatu materi masih sangat kurang.
\end{abstract}

Kata kunci: Relasi dan fungsi, pemahaman konsep, kesalahan siswa, analisis kesalahan Newman.

\begin{abstract}
Understanding the concept of mathematics is able to help students to solve math problems properly and corretly. However, based on data obtained from the Ministry of Education and Culture (2019), the average score for the National Examination in Indonesia in mathematics is the lowest among other subjects. Many students have difficulty solving problems because they do not understand the concepts being studied, one of which is on the relation and function material. Data from the Ministry of Education and Culture shows that only $27,14 \%$ of students can answer questions corretly, therefore researchers are interested in knowing where the mistakes that students often make in answering questions on relation and function material. This research is a qualitative descriptive study with 50 students as research subjects from one of the public junior high schools in Sleman Regency. The data collection technique was carried out by
\end{abstract}


giving 5 description questions and student answers were collected for analysis using Newman error analysis. The questions given refer to the characteristics of the validated concept understanding questions. The results showed that the highest number of errors made by students at the stage of understanding the questions was 33\% and the smallest errors were obtained at the transformastion stage, which was 5\%. This research is important to study because it sess students' understanding of the concept of a material that is still very lacking.

Keywords: Relation and functions, understanding of concepts, student errors, Newman error analysis.

\section{PENDAHULUAN}

\begin{tabular}{rrr}
\multicolumn{2}{c}{ Penguasaan konsep pada mata } \\
pelajaran matematika
\end{tabular}
memudahkan siswa untuk menyelesaikan soal matematika dengan baik dan benar. Matematika merupakan pelajaran yang membutuhkan ketelitian dan ketepatan setiap langkah dalam penyelesaian permasalahannya. Kesalahan pengerjaan matematika pada satu tahapan bisa menimbulkan kesalahan pada hasil akhir jawaban. Siswa yang mendapat nilai rendah pada mata pelajaran matematika bisa diakibatkan karena tidak mengerti konsep dan hubungannya dengan informasi yang ada pada soal.

Kemendikbud

mengungkapkan hasil rata-rata nilai Ujian Nasional mata pelajaran matematika menduduki peringkat paling rendah di antara mata pelajaran lainnya seperti Bahasa Indonesia, Bahasa Inggris, dan IPA. Pada Tahun 2019 capaian rata-rata nilai matematika di SMP sebesar 46,56 sedangkan di MTs sebesar 42,24. Begitu pula dengan rata-rata nilai Ujian Nasional pada tahun 2018, mata pelajaran matematika juga menduduki peringkat paling rendah. Capaian rata - rata nilai matematika di SMP sebesar 44.05 dan di MTs sebesar 41,16. Sebagian besar siswa mengalami kesalahan dalam menjawab soal pada materi aljabar, salah satunya pada materi relasi dan fungsi.

Analisis kesalahan siswa dimaksudkan untuk mengidentifikasi jenis kesalahan siswa berdasarkan hasil pengerjaannya mulai dari penulisan yang diketahui/ditanya, langkah menyelesaikan hingga penarikan kesimpulan. Hasil analisis bisa menjadi pedoman bagi guru untuk menata kembali cara pengajarannya pada materi selanjutnya atau pada materi yang sama bagi siswa-siswa tahun berikutnya. Analisis kesalahan yang dijadikan acuan pada penelitian ini adalah analisis kesalahan Newman (NEA). NEA (Newman's Error Analysis) merupakan jenis analisis yang dijadikan alat diagnostik sederhana untuk menemukan dan mengkategorikan kesalahan yang dilakukan siswa. Newman (Clemen, 1980) mengemukakan bahwa terdapat lima tipe kesalahan dalam mengerjakan soal matematika, yaitu kesalahan dalam membaca (reading), kesalahan dalam memahami masalah (comprehension), kesalahan transformasi (transformation), keterampilan proses (process skill), dan penulisan jawaban akhir (encoding).

Beberapa penelitian yang relevan dengan penelitian ini adalah: Siregar (2018) menemukan kesalahan yang 
dilakukan siswa pada kesalahan membaca sebesar 13,5\%, kesalahan pemahaman sebesar 44,8\%, kesalahan transformasi sebesar 57,3\%, kesalahan keterampilan proses sebesar 56,3\%, dan kesalahan penulisan jawaban akhir sebesar 79,2\%; Atikasari (2016) menemukan penyebab kesalahan membaca terjadi karena keliru memahami simbol dan mencatat informasi, Kekeliruan memahami masalah terjadi karena salah memahami tujuan soal, kesalahan transformasi terjadi karena salah memilih rumus yang diterapkan dan ketika melakukan operasi hitung, kesalahan kemampuan memproses terjadi karena salah memutuskan langkahlangkah yang tepat, dan kesalahan menulis hasil terjadi karena tidak memeriksa kembali pekerjaannya.

Berdasarkan uraian tersebut, penelitian ini diberi judul "Analisis Kesalahan Siswa Menyelesaikan Soal Pemahaman Konsep pada Materi Relasi dan Fungsi" dengan tujuan untuk mengetahui kesalahan siswa dalam mengerjakan soal pemahaman konsep.

\section{METODE PENELITIAN}

Penelitian dilaksanakan hari Selasa, 13 Oktober 2020 di salah satu SMP Negeri di Kabupaten Sleman. Jenis penelitian adalah deskriptif kualitatif. Subyek yang diteliti yaitu siswa kelas VIII dengan rentang usia 13-14 tahun. Subjek dipilih karena baru selesai mempelajari materi relasi dan fungsi. Subyek terdiri dari 50 siswa dengan kemampuan yang berbeda.

Teknik pengumpulan data dilakukan dalam jaringan dengan memanfaatkan google form dan aplikasi whatapps (WA) untuk komunikasi.
Subyek diberikan lembar kerja peserta didik (LKPD) yang berisi 5 soal uraian pemahaman konsep materi relasi dan fungsi. Subyek diminta untuk menjawab soal tersebut dalam waktu 90 menit. Soal dijawab dengan lengkap, disertai langkahlangkah pengerjaan dan dikerjakan secara mandiri sesuai kemampuan siswa. Soal tersebut dikerjakan pada kertas dan hasilnya dipindai lalu disimpan dengan format PDF, kemudian dikirim ke google form yang sudah disediakan.

Penelitian ini menggunakan instrumen, yaitu lembar kerja peserta didik (LKPD) yang sudah tervalidasi. Selain lembar kerja peserta didik, instrumen lain adalah google form untuk tempat pengumpulan jawaban dan ada pula lembar validasi soal yang juga dalam bentuk google form. Lembar validasi soal tersebut terdiri dari beberapa aspek, yaitu aspek kesesuaian materi, konstruksi, dan bahasa.

Teknik analisis data dilakukan dengan cara membagi dua jawaban yang sudah terkumpul. Lalu masing - masing peneliti menganalisis bagiannya berdasarkan analisis Newman. Pertama, lembar jawaban siswa dikelompokkan dengan memberikan kode tertentu menurut teori Newman seperti yang sudah dijelaskan dalam pendahuluan. Kedua, kode-kode yang sudah dikelompokkan dianalisis dan dihitung jumlah kesalahannya kemudian dihitung dalam satuan presentase. Ketiga, penggabungan hasil analisis dan jumlah kesalahan yang ditemukan oleh masing-masing peneliti. Data yang diperoleh adalah data terakhir yang akan disampaikan pada bagian hasil. 
Tabel 1. Hasil Validasi Soal

\begin{tabular}{lcl}
\hline \multicolumn{1}{c}{ Aspek penilaian } & $\begin{array}{c}\text { Nilai rata-rata dari } \\
\text { seluruh soal }\end{array}$ & $\begin{array}{c}\text { Catatan dosen secara } \\
\text { keseluruhan }\end{array}$ \\
\hline $\begin{array}{l}\text { Permasalahan sudah sesuai dengan } \\
\text { tujuan penelitian } \\
\text { Permasalahan bersifat pemahaman } \\
\text { konsep }\end{array}$ & 4,2 & \\
$\begin{array}{l}\text { Permasalahan dan pertanyaan } \\
\text { dirumuskan dengan singkat dan jelas }\end{array}$ & 4 & $\begin{array}{l}\text { Secara umum, soal sudah } \\
\text { menguji pemahaman } \\
\text { konsep siswa. }\end{array}$ \\
$\begin{array}{l}\text { Bahasa yang digunakan komunikatif, } \\
\text { mudah dipahami, dan tidak } \\
\text { menimbulkan penafsiran ganda }\end{array}$ & 4 & \\
\hline
\end{tabular}

Tabel 2. Hasil Analisis Kesalahan Secara Umum

\begin{tabular}{lccccccc}
\hline $\begin{array}{c}\text { Tipe } \\
\text { Kesalahan }\end{array}$ & $\begin{array}{c}\text { Soal } \\
\text { nomor } \\
\mathbf{1}\end{array}$ & $\begin{array}{c}\text { Soal } \\
\text { nomor } \\
\mathbf{2}\end{array}$ & $\begin{array}{c}\text { Soal } \\
\text { nomor } \\
\mathbf{3}\end{array}$ & $\begin{array}{c}\text { Soal } \\
\text { nomor } \\
\mathbf{4}\end{array}$ & $\begin{array}{c}\text { Soal } \\
\text { nomor } \\
\mathbf{5}\end{array}$ & $\begin{array}{c}\text { Total } \\
\text { kesalahan } \\
\text { pertipe }\end{array}$ & $\begin{array}{c}\text { Total } \\
\text { kesalahan } \\
\text { dalam } \\
(\boldsymbol{\%})\end{array}$ \\
\hline Membaca & 9 & 8 & 3 & 5 & 5 & 30 & $13 \%$ \\
Memahami & 19 & 24 & 14 & 9 & 8 & 74 & $33 \%$ \\
Transformasi & 6 & 5 & 1 & 0 & 0 & 12 & $5 \%$ \\
Pemrosesan & 17 & 13 & 1 & 7 & 0 & 38 & $17 \%$ \\
Pengkodean & 26 & 11 & 12 & 5 & 15 & 69 & $31 \%$ \\
\hline \multicolumn{7}{c}{ Total Kesalahan yang Diamati }
\end{tabular}

\section{Kesalahan secara umum}

HASIL PENELITIAN DAN PEMBAHASAN

Sebelum soal diujikan kepada subyek, peneliti membuat lembar validasi yang memuat 4 aspek penilaian. Validator soal ialah satu orang Dosen Pendidikan Matematika Universitas Sanata Dharma. Pemberian nilai tentang kelayakan soal dinyatakan dalam angka 1 sampai 5, seperti dalam Tabel 1. Nilai yang diberikan dosen tergolong baik. Dengan demikian soal yang diujikan kepada subyek valid. Kesalahan yang ditemukan dipaparkan di bawah ini.
Pada jawaban yang terkumpul dari 50 siswa, ditemukan sebanyak 223 bentuk kesalahan. Jumlah ini adalah akumulasi dari 5 jenis kesalahan Newman.

Tabel 2 menunjukkan bahwa kesalahan siswa paling banyak terjadi pada soal nomor 1 yakni pada tahap akhir penulisan jawaban. Sedangkan kesalahan paling banyak untuk semua soal terletak pada kesalahan memahami dengan jumlah 74 kesalahan.

\section{Kesalahan membaca}

Kesalahan membaca soal bisa berbentuk ketidakmampuan siswa dalam menuliskan lambang, notasi atau angka - 
angka yang diketahui dalam soal. Pada Gambar 1 terlihat bahwa siswa menuliskan jawaban yang sama sekali tidak berhubungan dengan maksud saol. Siswa tidak membaca kata-kata secara tepat, akibatnya siswa tidak bisa menuliskan hal-hal yang diketahui untuk selanjutnya ditransformasi.

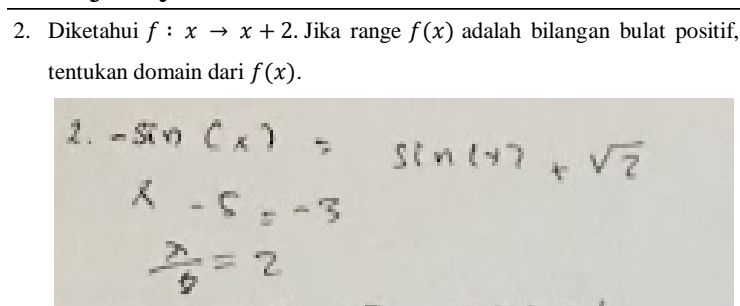

Gambar 1. Contoh kesalahan membaca

\section{Kesalahan memahami}

Siswa membaca soal dengan baik tapi tidak menuliskannya sebagai sebuah informasi yang jelas. Hal ini bisa terjadi karena siswa malas menuliskan hal yang diketahui atau karena waktu menuliskannya tidak cukup.

Kesalahan memahami biasanya karena siswa tidak menuliskan hal-hal yang ditanya secara lengkap dan tepat. Misalnya, Gambar 2 memperlihatkan jawaban yang tidak memuat informasi soal dengan lengkap. Akibatnya, prosedur yang dilakukan siswa tidak sesuai dengan perintah yang ada dalam soal.

Subyek memang menuliskan hal yang diketahui dan yang ditanya tetapi tidak lengkap. Siswa mengabaikan pekerjaan Anton dan langkah langkahnya hingga bisa menyimpulkan bahwa $f(x)=g(x)$, padahal itu sebenarnya poin penting untuk menyelesaikan soal nomor 1 .

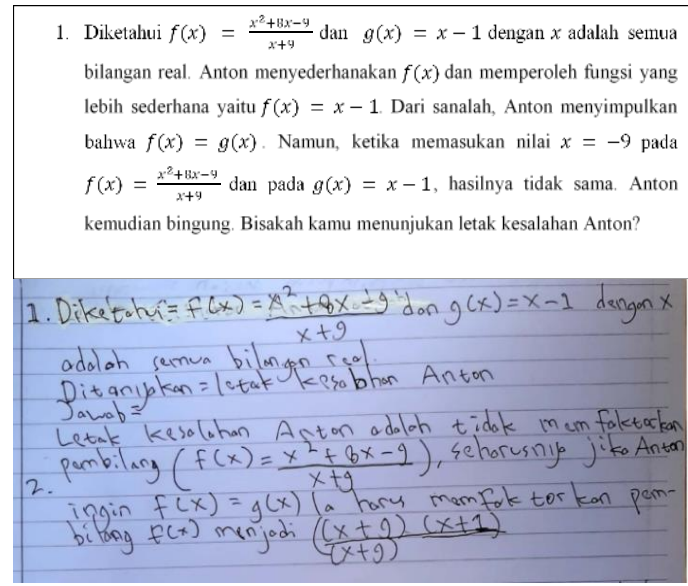

Gambar 2. Contoh kesalahan memahami soal

\section{Kesalahan transformasi}

Menurut Singh (2010: 266), " $a$ transformation error occured when the pupil had corretly comprehended a question's requirement but failed to identify the proper mathematical operation or sequence of operation to seccesfully pursue the course of problemsolution".

Kemungkinan penyebab kesalahan transformasi adalah kelemahan siswa dalam menyesuaikan operasi yang dibutuhkan soal. Penelitian ini menunjukkan bahwa kesalahan transformasi pada subyek tergolong sangat kecil dibanding pada tahapan yang lain. Bahkan pada soal 4 dan 5, tidak ditemukan kesalahan siswa yang tergolong pada tahapan ini.

Hal ini berbeda dari hasil penelitian Qutotaa'yun (2016) yang menemukan bahwa terdapat 29,33\% kesalahan transformasi. Kesalahan ini berada pada urutan kedua terbanyak, yaitu setelah kesalahan pemahaman sebesar 42,67\%. Angka ini masih terlalu besar dibanding kesalahan transformasi yang ditemukan pada analisis ini sebesar 5\%. 
Menariknya, kesalahan transformasi tersebut kebanyakan terdapat pada soal 1 dan 2.

1. Diketahui $f: x \rightarrow x+2$. Jika range $f(x)$ adalah bilangan bulat positif tentukan domain dari $f(x)$.

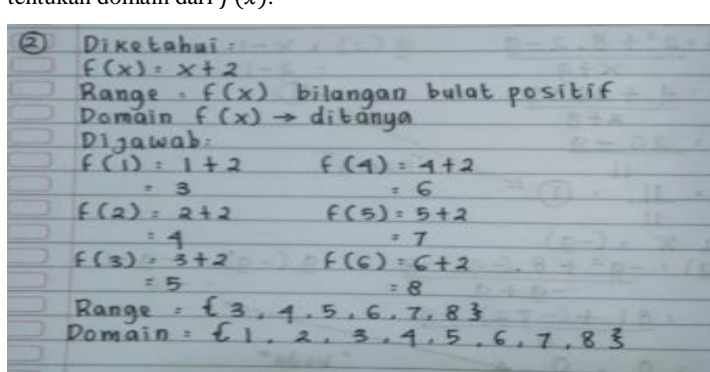

Gambar 3. Contoh kesalahan transformasi

Perhatikan Gambar 3, kesalahan subyek terletak pada pemilihan cara yang sesuai dengan permintaan. Subyek mensubstitusikan nilai $x$ sehingga seolaholah nilai $x$ yang mengakibatkan $f(x)$ bernilai positif adalah domain dari fungsi tersebut. Padahal, domain dari $f(x)$ tidak bisa diukur dengan cara seperti itu karena cakupan dari $x$ sangat luas. Siswa gagal dalam mentransformasi soal pada pelajaran tentang operasi pengurangan dan penjumlahan pada pertidaksamaan satu variabel.

\section{Kesalahan pemrosesan matematika}

Kesalahan pemrosesan matematika dapat dilihat dari jawaban yang tidak tepat dalam melakukan perhitungan, penggunaan kaidah atau aturan yang tidak tepat atau tidak mampu menyelesaikan jawaban. Berdasarkan Gambar 4, terlihat bahwa aturan yang dipilih siswa tidak sesuai dengan permintaan soal. Siswa sudah mampu memahami soal dan menggunakan operasi yang tepat, tetapi salah dalam menentukan aturan $x+2$ agar bernilai bilangan bulat positif. Siswa memberikan nilai $f(x)=1$, sehingga diperoleh nilai $x$ yang me-menuhi adalah -1. Tentu saja ini tidak sesuai dengan aturan dalam menentukan domain suatu fungsi.

2. Diketahui $f: x \rightarrow x+2$. Jika range $f(x)$ adalah bilangan bulat positif, tentukan domain dari $f(x)$

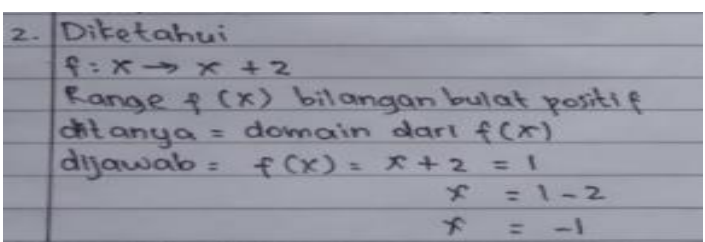

Gambar 4. Contoh kesalahan pemrosesan matematika

$$
\text { Zanthy dkk (2019) pada }
$$
penelitiannya tentang analisis Newman pada materi barisan dan deret menyatakan bahwa kesalahan pada tipe pemrosesan adalah kesalahan paling banyak ditemukan. Nurul Hidayati Arifani, Abdur Rahman As'ari \& Abadyo (2016) menyatakan kesalahan pemrosesan juga terletak pada urutan pertama, sejajar dengan kesalahan memahami. Hasil penelitian tersebut senada pada hasil penelitian ini. Kesalahan pemrosesan terletak pada urutan keempat terbesar. Ini mengisyaratkan kenyataan siswa belum mampu menerapkan aturan-aturan yang benar dalam menyelesaikan persoalan matematika.

\section{Kesalahan penulisan jawaban akhir}

Kesalahan penulisan jawaban akhir yang ditemukan pada penelitian ini lebih banyak terdapat pada soal nomor 3 dan 5. Kesalahan penulisan jawaban adalah kesalahan siswa pada bagian akhir jawaban. Misalnya, siswa tidak menuliskan kesimpulan pada jawaban yang didapat atau menuliskannya tapi kurang tepat. Menurut Wijaya (2014), kesalahan 
penulisan jawaban akhir adalah ketidakmampuan siswa untuk menafsirkan dan memvalidasi solusi matematika dalam konteks dunia nyata. Berikut disajikan beberapa contoh jawaban siswa yang salah pada tahapan ini.

1. Misalkan terdapat himpunan $A$ dengan $n(A)=5$ dan himpunan $B$ dengan $n(B)=6$. Apakah memungkinkan fungsi $f: A \rightarrow B$ disebut korespondensi satu - satu? Mengapa?

3. diket

$\Lambda(A)=5$

$n(B)=6$

ditarya: munglinkah Mengapa?$$
\text { jub: }
$$

Jub:

Gambar 5. Contoh kesalahan penulisan jawaban akhir

Pada Gambar 5, siswa sudah benar membaca soal, menuliskan yang diketahui dan yang ditanya dengan benar, sudah mampu mentransformasi konsep yang digunakan, akan tetapi salah dalam menuliskan kesimpulan. Seharusnya, salah satu syarat korespondensi satu satu adalah jumlah domain harus sama dengan jumlah kodomain. Sedangkan yang dituliskan siswa sebagai alasan adalah jumlah range dan domainnya tidak sama. Penelitian ini menemukan banyak jenis kesalahan penulisan jawaban akhir pada penulisan kesimpulan pada soal nomor 5 .

\section{KESIMPULAN}

Disimpulkan bahwa analisis kesalahan Newman adalah analisis yang baik digunakan dalam soal pemahaman konsep. Diperoleh bahwa jumlah kesalahan terbanyak yang di-lakukan siswa adalah pada tahapan me-mahami soal yakni 33\%. Banyak siswa yang tidak menuliskan hal - hal yang diketahui dan yang ditanyakan pada soal atau dituliskan tetapi tidak lengkap. Adapun contoh kesalahan pada tahapan membaca yakni siswa menuliskan jawab-an yang sama sekali tidak diketahui pada soal dan juga tidak memiliki hubungan dengan topik yang diujikan. Kesalahan paling kecil diperoleh pada tahapan transformasi sebesar $5 \%$.

Peneliti memberikan saran kepada guru, yaitu untuk melatih siswa mengetahui pokok materi secara mendasar, berbasis pertanyaan mengapa dan bagaimana, selalu merujuk pada hukum sebab akibat dan keterkaitannya dengan materi - materi yang lain. Hal ini dimaksudkan agar siswa tidak kesulitan jika menemui soal - soal dalam topik yang sama dengan berbagai variasi.

Peneliti memberikan saran kepada peneliti selanjutnya yang ingin menggunakan analisis kesalahan siswa menurut analisis Newman, yaitu sebaiknya melakukan wawancara kepada beberapa subyek agar pada bagian pembahasan dapat dicantumkan alasan - alasan siswa salah dalam mengerjakan soal. Selain itu, dalam hal pembuatan soal disarankan untuk menanyakan pendapat guru yang mengajar subyek agar terhindar dari kemungkinan soal belum dipelajari atau sudah dipelajari tetapi tidak sesuai.

\section{DAFTAR PUSTAKA}

Arifani, N.H. As'ari, A.R. \& Abadyo. (2016). Analisis Kesalahan Siswa dalam Menyelesaikan Soal Matematika Timss Menurut Teori Newman. Seminar Nasional Matematika dan Pendidikan Matematika UNY.

Atikasari, F. (2016). Analisis Kesalahan Siswa Kelas VIII dalam 
Menyelesaikan Soal Pemecahan Masalah Berdasarkan Analisis Newman pada Pembelajaran PBL. Universitas Negeri Semarang.

Clemen, M.N. (1980). The Newman Procedure for Analysing Errors on Written Mathematical Tasks. Educational Studies in Matheatics.

Kemdikbud. (2019). Laporan Hasil Ujian Nasional.

https://hasilun.puspendik.kemdikbu d.go.id/\#2019!smp!capaian_nasiona 1!99\&99\&999!T\&T\&T\&T\&1\&!1! \&.

Koli, Y.F. (2019). Analisis Kesalahan Siswa dalam Menyelesaikan Soal Matematika pada Materi Relasi dan Fungsi. Universitas Katolik Widya Mandira Kupang.

Oktaviana, D. (2017). Analisis Tipe Kesalahan Berdasarkan Teori Newman dalam Menyelesaikan Soal Cerita pada Mata Kuliah Matematika Diskrit. Edu Sains: Jurnal Pendidikan Sains dan Matematika, 5(2):22-32.

Qurotaa'yun, U.N. (2016). Analisis Kesalahan Siswa dalam Menyelesaikan Soal Cerita Persamaan Linear Satu Variabel. Universitas Muhammadiyah Surakarta.

Satiti, T. (2014). Analisis dengan Prosedur Newman terhadap Kesalahan Peserta Didik Kelas VII dalam Menyelesaikan Soal Pemecahan Masalah Matematika. Universitas Negeri Semarang.

Septiahani, A., Melisari, M. \& Zanthy, L.S. (2020). Analisis Kesalahan Siswa SMK dalam Menyelesaikan Soal Materi Barisan dan Deret. Mosharfa: Jurnal Pendidikan Matematika, 9(2): 311-322.
Siregar, D.P. (2018). Analisis Kesalahan Siswa dalam Menyelesaikan Soal Cerita Matematika Berdasarkan Prosedur Newman. Universitas Muhammadiyah Sumatera Utara. 